animal must belong to a much larger and quite distinct species, of which we trust it will not be long before perfect examples are received in Europe.

The significance of the discovery of a species of Tachyglossus in New Guinea will be appreciated when we consider that hitherto the Monotremes or Ornithodelphs, which, according to the most recent authorities, constitute not merely a distinct order, but even a separate sub-class of mammals, have been supposed to be at present exclusively restricted to Austratia. The two only known genera of Monotremes are Tachyglossus (sive Echidna) and Ornithorhynchus. Of the latter the single known species is peculiar to South-Eastern Australia, of the former, the two species are found, one in South.Eastern Australia, and the other in Tasmania. The whole of the north and west of the Australian continent is, so far as we are at present informed, without any representative of this remarkable group. Looking at these facts, the discovery of a species of Monotreme in New Guinea becomes still more significant, and leads us to expect that when the mountain-ranges of Queensland have been further explored, some representative of the order may still be found lingering in this district, and uniting the newlydiscovered area of distribution with that previously known.

Finally we may remark that the fundamental unity of the Papuan and Australian fauna was already sufficiently obvious by the existence amongst mammals of Macropus and amongst birds of such peculiar genera as Orthonyx and Climacteris in New Guinea. The discovery of Tachyglossus bruijnii is another confirmation of the correctness of this view, as regards zoology, though, as regards the flora of New Guinea, facts, we believe, point rathe $\mathrm{r}$ in another direction.

P. L. S.

\section{ON THE TROPICAL FORESTS OF HAMPSHIRE ${ }^{1}$}

\section{II.}

$\mathrm{T}$ has been mentioned that in some of the clays remains of leaves, fruits, and flowers are met with, and I will now proceed to tell you something about them. There are some enlarged drawings here on the wall which I should tell you are not all enlarged to equal scale, and there are trays of specimens on the table.

These leaves are found in various conditions of preservation. In most cases the impression only of the leaves in the clay is met with, but in some cases they are so well preserved that the actual substance has been retained although chemical changes have altered its composition and it will peel off and blow away. In some of the clays the masses of leaves are so decayed that they cannot be recognised, and are not worth our collecting.

Where the preservation is good we can readily distintinguish the various original textures of the leaves by comparing their general aspect and colour both among themselves and with existing forms. For instance, those which are thick, such as evergreens, thin, as convolvulus, hard, such as oak, or soft, such as lilac, or even velvety, such as the common phlox, can all be recognised. Their colours, in most of the beds, vary from buff to brown, but I need hardly tell you that in no case have we any of the green colouring of the leaves preserved. Whilst these various shades of dark buffs and browns are in many cases the result of chemical change that has taken place after the leaf was covered up, yet I believe that in many cases this change had occurred, at least partially, before the covering up, just as we saw a few weeks ago the changed colours of the fallen leaves of autumn.

In the darker clays the remains are black and com-

Lecture in connection with the Loan Collection of Scientific Apparatus, given at the South Kensington Museum, December 2, 1876, by J. Starkie Gardner, F.G.S. Continued from p. 233. pletely carbonised; where this is so the finer venation is indistinct and the remains difficult to save, so that we may discard them unless the outline of the leaf is of unusual form. The darker browns, I take it, indicate hard and evergreen leaves; for instance, the laurtl-like leaves are always of a deep colour, whilst both the thin and the succulent leaves are always of light colour, as in the leaves which we suppose to be fig, some species of smilax, \&c.

No other colours have been met with with one remark able exception ; fragments of a reed-like aspect are found of a deep violet, staining the surrounding clay mauve for a considerable distance.

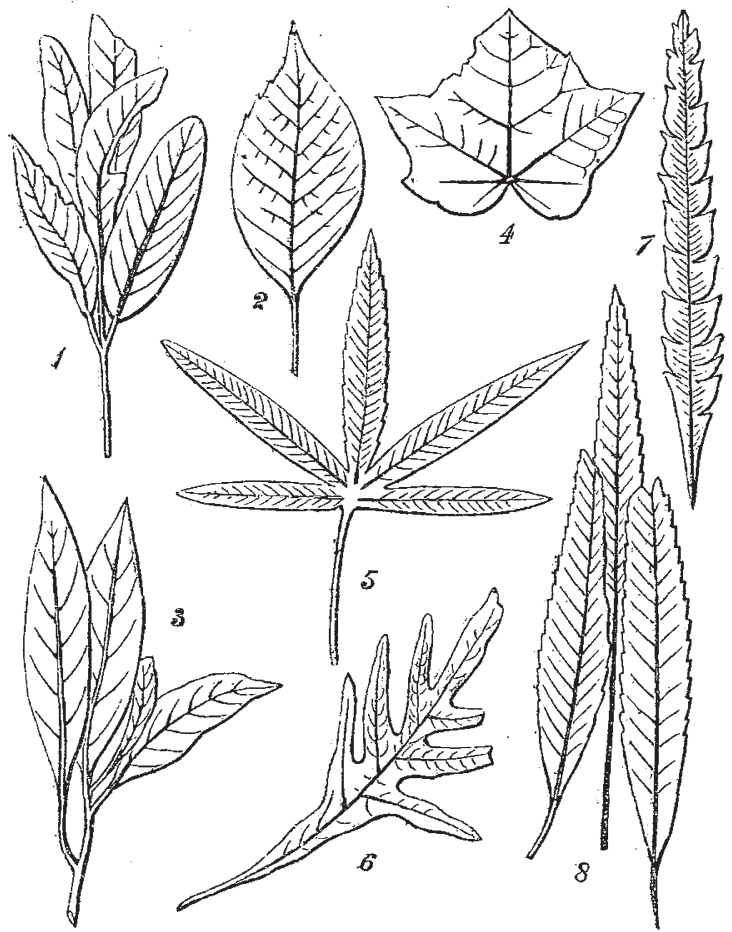

Fig. 4 -Leaves of Dicotylepons, from the Lower Bagshot Beds. $x$ and 2, Fagus : 3, Laurus: 4 , Acer; 5, Aralia (?); 6, Stenocarpus : 7. Dryandra; 8, Quercus.

I next call attention to the shapes of these leaves; the most cursory examination shows that the differences in shape are very great. Here are drawings of palmate leaves, leaves resembling in general shape the beech, the sub-tropical Dryandra, which, though unfamiliar, have been probably seen by most of you in the warmed houses at Kew ; laurel-like leaves, a tropical kind of oak, maple, smilax, aralia, yew, palms, and a fern. These have been selected to show the great diversity in the shapes which existed.

Most people are familiar with the process of skeletonising leaves - that is, the removal of the green part, and the preservation of what is called the skeleton. I have here a large case of leaves so prepared by Mrs. J. E. Gardner, and which may be examined at the close of the lecture.

I would next draw attention to some leaves of trees which are well known as now growing in England. In these a continuation of the leaf-stalk can clearly be distinguished running through the leaf, which is commonly called the mid-rib. [The mid-ribs in two diagrams were co'oured red.] Those running from the primary ribs are called secondary ribs (coloured blue). There are, again, running from these many smaller portions, which are called the network of the skeleton. In some, as, for example, the plane-tree, there are three primary ribs; in a few leaves 
there are more. In some, these principal ribs are very strong, and form prominent features ; in others, as in the convolvulus, they are but slight. Some of these secondary ribs run straight to the margin, and in other cases they are curved. Again, in some they run right out to the extremity of the margin, as in the elm; and in others they are curved back, as in the fig. These are things to be noticed, which it will be seen are of consequence.

I wish now to refer to the character of the margins of the leaves. Here is a drawing of a fig leaf in which a perfectly smooth margin will be observed; whilst the elm is saw-like, or serrated, as botanists call it. In the dryandra the margin is deeply notched, whilst in a strange-looking form (Stenocarpus) the edge is markedly lobed; in the case of some palmate leaves the edge is smooth, as in the passion-flower, or serrated, as in the fossil aralia. Those who have paid any attention to leaf form, have no doubt observed that leaves, even from the same plant, differ in some of these characters. This constitutes one of the greatest difficulties which presents itself to the botanist, in the endeavour to decide by comparisons to what plants the fossil remains probably belonged. Still, there are numbers of specimens with which we have to deal presenting forms so unmistakably alike that we are able to group them together; and even putting on one side many fossil forms about which we must feel considerable hesitation, there still remain a vast number about which we can feel little hesitation as to the value of the comparisons.

It is worth while to point out that when we compare these leaves with the existing flora and contrast in like manner the plants of the coal period with the existing vegetation, we see that there is a much closer resemblance between these plants and the present plants than there is in the case of coal plants. That is, that in these forins we have a nearer approach to the existing state of things than there was in the coal period, a matter which, in viewing the evolution of plant life, cannot be overlooked, whatever may be the value to be set on such evidence. Those who know anything of the plants of the coal period are aware that we find there gigantic forms of which we have only dwarf representatives at the present time. The principal of these forms are gigantic horsetails or Equisitaceæ, great lycopods, as the Lepidodendron and Sigillaria, and tree-ferns, all very unlike the representatives of these groups now living. Here, however, the resemblances to the existing vegetation is close, not only in the arrangement of the ribs, but the size of the leaves, and also in those cases where we have groups of leaves joined by twigs, the method of attachment is similar.

To determine to what kind of plants each of these leaves belongs is a matter of considerable difficulty and requires an extensive knowledge of the plants now living on the earth. Although we have collections of growing plants from different parts of the world in various conservatories, such as at $\mathrm{Kew}$, it is on the dried specimens brought home by travellers, or sent from abroad, that we mainly have to depend. How frequently leaves closely resembling each other but belonging to plants of widely different kinds are met with, the careful student of botany knows well. It requires a comparison by a skilled eye of the most minute details to arrive at conclusions on which any reliance may be placed.

The work of comparison of this immense number of leaves is necessarily a work of considerable time, and is still in progress, but some conclusions have already been arrived at. I call your attention to a large group of growing plants, from the conservatory of Mrs. J. E. Gardner, which illustrate the kind of foliage existing in England in the Eocene time. Those who have paid attention to this subject will not doubt that these are palms; these are unmistakable ferns ; botanists are agreed that this form is undoubtedly referable to the group to which this dryandra belongs; this may with almost certainty be referred to the beech tribe; this doubtless belongs to the same tribe as the pea; this is an aralia; this an acer or maple; this a laurel, and this a yew. Specimens of elm, acacia, chestnut, great aroids, as well as hundreds of other forms, have been obtained, some of the comparisons of which have already been determined, and some few are of forms which appear to have noliving analogies whatever. There are also countless fruits, many of which can be recognised as like those now existing; a few flowers too have been met with. These fruits are of great assistance in telling us what plants were living at the time, as they are compared with greater certainty than the leaves can be.

I have mentioned the cabinets in the Loan Collection; close by is a cabinet which contains the collection made by Baron von Ettingshausen, and although time does not permit me to do more than allude to them, I would just mention that collections of an approximately similar geological age have been made from $S$ witzerland, Italy, Greenland, and Austria, so that taking together all these localities we get a fair notion of what was the vegetation of the period which geologists call Eocene. You must remember geology is a study only of this century. Interest, at first small, spreads now over all Europe, and gradually records of past vegetations of different ages are being brought to light and compared.

I would say a word or two by way of explanation of the origin of the different colours of the sands and clays which have been mentioned. The yellows, buffs, and reds, which form the prevailing colours of the lower series, ove their origin to iron in various chemical conditions. The granite from which they were derived contains sufficient iron to account for iron being in solution in the streams by which they were deposited. The different colours of the different oxides of iron are here shown. The anhydrous sesquioxide is of a deep tinge: the hydrous sesquioxide gives a yellow colour. [A successful experiment was then made with a large glass jar of rain-water with dissolved grey granite held in suspension. To show the amount of iron present in the granite, a little ammonia was added, which changed it to a dark colour. The green exide thus obtained wculd, on evaporation of the water, take another degree of oxygen and change to a bright red sesquioxide. This red oxide was produced in a second jar, and shown to be the same as the colouring matter of the red clays.] De la Beche, in his researches in theoretical geology, alludes to the fact that pipe-clays of similar colours are now being deposited in some of the lakes of North America.

Whilst some of the dark colouring of the darker clays is due to iron, that of some of the middle clavs may be due to the fact that, whilst these beds were being deposited, the source of the stream was coming from a district farther north, cutting perhaps across the Somersetshire and Gloucestershire coal-field.

The question may perhaps have presented itself to your minds-how is it possible that the tropical forms of which we have spoken, such as the palm, aroids, cactus, \&c., could have grown alongside of the apparently temperate forms, such as the $n a k$, elm, beech, and others. Time does not allow that I should go at any length into the explanation of this; but I may just remind you that in the long geological record of the beds found in England, there are to the geologist unmistakable indications of many changes in climate. Further, astronomers, having calculated the path of the revolution of the earth in ages past, tell us that in successive periods, each consisting of about 26,0co years, each hemisphere, northern and southern, has been successively subject to repeated cyclical changes in temperature. There have been for the area which is now England many alternations of long periods of heat and cold. Whenever the area became warmer, the descendants of semi-tropical forms would gradually 
creep further and further north, whilst the descendants of cold-loving plants would retreat from the advancing temperature. Vice versá, whenever the area became gradually colder, the heat-loving plants would, from one generation to another, retreat further and further south, whilst the cold-loving plants would return to the area from which their ancestors had been driven out. In each case there would be some lingering remnants of the retreating vegetation (though perhaps existing with diminished vigour), growing alongside of the earliest arrivals of the incoming vegetation. Such is a possible explanation of our finding these plant remains comingled together. It must, too, be borne in mind that it is not so much the mean temperature of a whole year which affects the possibility of plants growing in any locality, as the fact of what are the extremes of summer and winter temperature. For example, one place may have a mean winter temperature of $50^{\circ}$, and a summer one of $70^{\circ}$; while another place might have a mean winter temperature of $20^{\circ}$, and a summer one of $100^{\circ}$, and yet both have a mean annual temperature of $60^{\circ}$. In Cornwall the maiden-hair fern grows in sheltered localities, because the winter tempera-

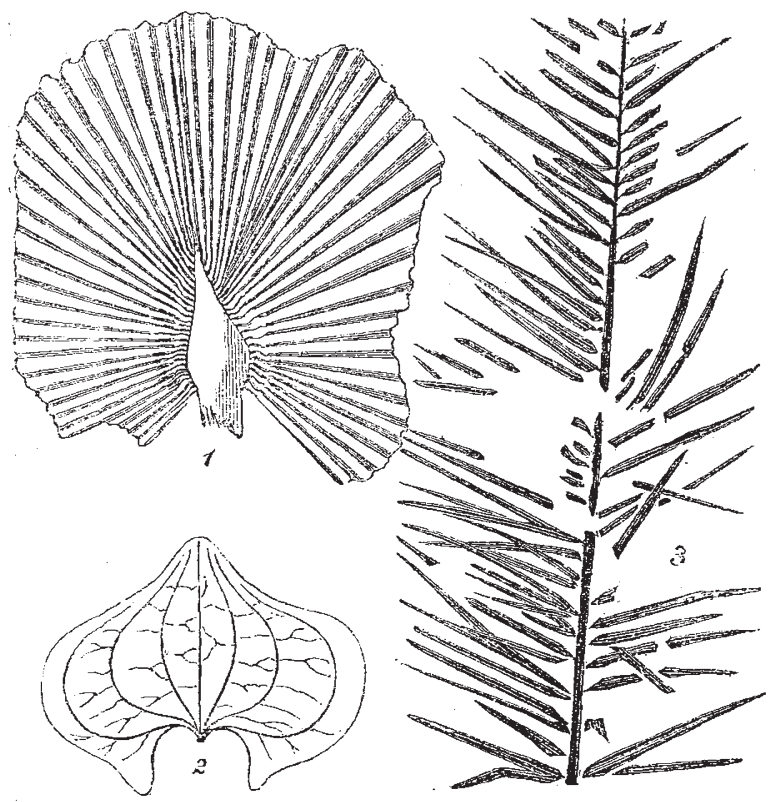

Fig. 5. - Grour e f Monocotylenons, from the Lower Bagshot Beds. r, Fan Palm;2, Smilax; 3, Feather Palm

ture never sinks to the point that would carse its destruction. Again, at that most charming spot in the west of Ireland, Glengariff, the arbutus still forms an abundant underwood; and the Irish filmy fern flourished in many favoured spots until quite recently, when the modern, too comfortable Eccles Hotel has retained tourists in the district, who have 1 uthlessly carried off, as reminiscences of a pleasant holiday, this which was one of the most attractive features to the botanists.

These facts, which seem so simple when laid out in diagrams, are the results of long-continued and careful work; but you may take my word for it, having enjoyed the pleasure during my holidays for many summers, that hunting for fossils is a fine, healthy and active exercise. As regards this particular district, let me tell you some of my experiences. Fossils are not to be obtained here without hard work; the steep and crumbling cliffs have to be climbed, and most diligent search has to be made for indications of them. Fifty times, perhaps, the cliff may be laboriously scaled to examine what appears from the beach to be a promising-looking patch of clay, to result only in disappointment; either the clay turns out to be too sandy, and the impressions valueless ; or it contains nothing; or it is found, on nearing it, to be inaccessible. But supposing well-preserved leaf-impressions reward the search, a secure footing has first to be cut with a light pickaxe; then the sands or clays overlying the leaf-bed have to be removed by spade and pick-real navvy's work this-then to get out blocks large enough to contain the palm-leaf shown in this drawing, which is only enlarged twice, the leaf-bed has to be undermined to a depth of five or six feet, a difficult operation requiring patience, and the then hanging mass of clay has to be cut off with the pick, being too plastic to break away by its own weight. When nearly cut through, it gradually breaks away, and falls gently on to the platform prepared for it underneath. The blocks thus obtained are sometimes too large for three or four men to tilt over. The method is then to leave them to dry, as when wet the clay will not split to disclose the leaves. It is then, I can assure you, that I esteem myself fortunate if some too curious excursionist, or enthusiastic townsman, does not arrive during my absence with a hammer to break the blocks up. So great has been the curiosity excited, that fossilizers have so far forgotten their sense of justice as to get up at daybreak to appropriate the result of my work had not the faithful coast-guardsmen, with a keener sense of justice, been near.

Wet weather of course puts a stop to operations, and buries the working in mud and sand, sometimes two or three feet deep even in a single night. When the workings are as far off from your headquarters as at Poole Harbour, and the specimens heavy, a boat is necessary to convey them home. The most enjoyable moments are, perhaps, those occupied in splitting the blocks, as one then shares what I should suppose to be the excitement of gold-workers, except that gold-finding must be more monotonous, as in this case no one can say what sort of treasure may reward us next. Anyhow, it is a recreation strongly to be recommended to those who like healthy exercise, freedom, and the sea.

[A large and heavy block of matrix was then split, in illustration of this part of the lecture, and a layer showing huridreds of leaves, exposed for the first time to view.]

I have now endeavoured to give you as accurately as I can, the absolute facts as far as we can learn them, respecting the conditions under which these beds were deposited, the sources from which the material was derived, and so far as we can tell, by comparison with existing vegetation, what were the trees of which these leaves are the records, and also the climatal conditions under which they grew. We may now, in conclusion, allow our imagination to come into play, a scientific use of the imagination, I hope it is, while we picture to ourselves the appearance of this area during the time these beds were being formed. The changing force of the streams and their directions varying from time to time, would, as we have already said, frequently undo the work of accumulation which had been previously done.

We have reason to believe that there was here a width of valley closed in to the north by the chalk hills which are still represented by the chalk range of North Hampshire and Wiltshire, and on the south and east by accumulations forming the lagoon barrier of which I have spoken. The course of the stream was from west to east. To the east was the sea, to the west was the valley of the stream, about some of the conditions of which we are necessarily uncertain, in consequence of the changes from upheaval and denudation, which have extensively modified that district. When the streams were from the rainy scasons swollen they moved along at a rapid rate, sweeping away previously deposited beds and also bringing down coarse quartz grit and blocks, which formed the gritty beds of which I have spoken. When the streams were not so violent then there were doubtless frequently 
repeated scenes such as I will now attempt to describe to you. In this ideal picture I have endeavoured to depict what I consider to have been the state of things. Here we have the valley of the river some six or seven miles broad. The streams reduced to streamlets meandering through dried and barren sand-banks. Among them are more elevated patches-islands, if we may use the term islands standing up from the general expanse of sand, and in some cases actual islands in the sense that they were surrounded by water. Here and there pools of water, some almost stagnant, others fed by minute streamlets.

Looking at the scene from a southern standpoint we should see to the north the distant chalk range. Whilst along the shore of the opposite bank of the valley we could with some difficulty detect the various forms of vegetation, which we should see with greater clearness in the more immediate foreground. In this valley a singular stillness must have prevailed, as no trace of animal life whatever has been found, except a feather and a few insect wings blown in from the southern bank.

Of the following at least we are pretty sure, and of numerous others we can be almost sure, but there are indications of very many besides, the relationships of which are at present but imperfectly defined.

Here we should see the graceful fan-palm and the feather palms, adding softness to the view by their elegantly-curved and drooping leaves, laurel and dwarfed oak, stately beeches, clumps of feathery acacia, trellised and festooned with smilax, the trailing aroid, with its large and glossy foliage and an undergrowth of Mimosa and of cypress in the swampier ground, and variations in colour caused by the foliage of cinnamon and fig, and the ground clothed with ferns and sedges. On the barren sands of the distant valley are growing clumps of giant and weird-looking cactus. It is not difficult to picture to ourselves the view. (See Fig. 2.)

All this beauty is gone. We have nothing but these records of what must have been a view of great loveliness, which only the toil of the geologist can even faintly reproduce.

"The hills are shadows, and they flow

From form to form, and mothing stands;

They melt like mist, the solid lands,

Like clouds they shape themselves and go.

"There rolls the deep where grew the tree.

O Earth, what changes hast thou seen!

There where the long street roars, hath been

The stillness of the central sea"

\section{THE REPORT ON THE AUSTRIAN "NOVARA" EXPEDITION}

A FW days ago Admiral v. Wüllerstorff Urbair, late A Commander-in-Chief of the Austrian Novara Exploring Expedition, had an audience of the Emperor to present to his Majesty the final report on the scientific results of this great exploring cruise round tine world. It has required about seventeen years' serious labour, and has cost nearly $13,000 \mathrm{l}$. sterling to complete this important scientific work, embracing 18 vols. 4 to. and 3 vols. 8 vo., and containing the anthropological, botanical, geological, zoological, physico-nautical, statistico-commercial, medical, and descriptive parts.

The narrative of the expedition, written by Dr. Karl von Scherzer (an author also well known in England, and at present attached to the Austro-Hungarian Embassy in London), has mes with such a success that five editions have been published and more than 29,000 copies sold.

The most interesting of the purely scientific publications is the geological "part, by Dr. Hochstetter, which gives the most complete description of the geology of New Zealand, the author having been the first naturalist who thoroughly explored these antipodean islands, and he has carefully examined and described its gold and coal deposits. The statistico-commercial part, by Dr. Karl von Scherzer, has become quite a standard book on the Continent.

The price of the complete series being very high (39r florins, or nearly $40 l$. sterling), the Emperor has given permission that a considerable number of copies of this most valuable publication should be given away to public institutions and libraries in the empire, as well as in foreign countries, and as the Novara has met with a particularly kind reception in the British colonies, the libraries of these have been considered first in the list of recipients of this great national work, which is a monument of scientific investigation.

\section{THE CYCLONE WAVE IN BENGAL}

$A N$ interesting correspondence on this subject has apA peared in the Times during the last few days, evincing generally on the part of the correspondents an earnest effort to arouse the public mind to a sense of the necessity of something being done towards mitigating the calamitous results of such occurrences in the future. The subject being one that must sooner or later be faced, it is beside the question to point to the destructive flooding of the Thames as a proof that the Government of India does not differ greatly in such matters from similar authorities at home.

As regards the meteorology of this important question, three lines of inquiry stand prominently out as calling for special and extended investigation. The first of these is a thorough discussion of the storms of the Bay of Bengal, or a continuation of the work under this head which has been ably begun by Mr. Blanford and Mr. Willson. The second line of inquiry is the cause or causes which originate the cyclone wave and determine the course it takes-a subject on which we cannot be said to have any information at present, all that is or can be said being little more than unsatisfactory conjectures. To carry out these inquiries with the fulness and with the detail required to ensure a successful handling of the subject additional stations must be established and the taking of meteorological observations must be more extensively and frequently done than is now the practice on board the ships which navigate the Bay.

The third line of inquiry is the systematic inauguration of a meteorological survey of the Bay of Bengal and its shores, with a more strict reference to its storms, by having first-class meteorological stations established at Trincomalee, Madras, Vizagapatam, False Point, Saugor Island, Chittagong, Akyab, Cape Negrais, the Andaman and the Nicobar Islands, these stations having a full equipment of instruments, including in each case a continuously registering barometer and anemometer. With these instruments the law of the diurnal oscillation of the barometer and of the changes in the direction and velocity of the wind, including the variations with season, would become known, and any deviation therefrom which may happen to occur, could be telegraphed at once to the head office at Calcutta. It may be regarded as absolutely certain, that no long time would elapse before the nature of the disturbing force, cyclonic or otherwise, revealed by the anomalous readings of the barometer and anemometer would come to be correctly interpreted; and with the aid of frequent telegrams from the whole circuit of stations, so well interpreted that the superintendent at Calcutta would have no difficulty in localising the cyclone, its track and rate of progress would be so certainly known that warning could be sent to the coasts threatened by it.

This system of storm warnings must not be confounded with that practised in Great Britain, in which no refined system of observations is called into play, and in which no accurate knowledge of mean periodic changes is required. What is chiefly required in this country is a 